Archived version from NCDOCKS Institutional Repository http://libres.uncg.edu/ir/asu/

\title{
Appalachľan
}

$\overline{\text { B O O N E, N O R T H C A R O L I N A }}$

\section{Maximum Hyoid Displacement In Normal Swallowing}

\author{
By: Youngsun Kim \& Gary H. McCullough
}

\begin{abstract}
Vertical and anterior displacement of the hyoid bone is a critical biomechanical component of normal swallowing function. The purpose of this study was to evaluate the maximal vertical and anterior displacement of the hyoid bone during oropharyngeal swallowing. A retrospective review of video-fluoroscopic swallowing exams in 40 normal subjects varying by age and gender was performed. Means and standard deviations for both vertical and anterior displacement were analyzed on both 5-ml and 10-ml thin liquids using an ImageJ program. Age and gender differences were submitted to a repeated-measures one-way analysis of variance. There was a significant difference between younger and older subjects for anterior displacement of the hyoid bone during the swallow but not for vertical displacement. No significant differences between male and female subjects were observed. Anterior displacement of the hyoid bone decreased with increasing age. This reduction may be related to muscle weakness. However, older people may adapt to preserve airway protection.
\end{abstract}

Youngsun Kim \& Gary H. McCullough (2008) "Maximum Hyoid Displacement In Normal Swallowing" Dysphagia 23:274-279 Version of Record Available At www.springer.com [DOI $10.1007 / \mathrm{s} 00455-007-9135-\mathrm{y}]$ 


\section{Maximum Hyoid Displacement in Normal Swallowing}

The purpose of swallowing is to safely transport food from the mouth to the stomach. Safe and proper ingestion of food and liquid is critical to survival. Swallowing can be divided into three physiologic stages: oral, pharyngeal, and esophageal [1]. As a bolus is propelled from the oral cavity into the pharyngeal cavity, the pharyngeal stage of the swallow is triggered. The pharyngeal swallow is complex and requires a series of events to occur in a timely fashion. These events include (1) vertical and anterior displacement of the hyoid bone and thyroid cartilage, (2) tilt and seal of the epiglottis, (3) closure of the true and false vocal folds, and (4) opening of the upper esophageal sphincter (UES) [2]. These activities must occur in synchrony with initial oral bolus propulsion and contraction of pharyngeal constrictors which propel the food or liquid through the pharynx and into the esophagus.

Vertical and anterior displacement, or "excursion," of the hyoid bone occurs as the bolus passes into the pharynx and is the most common marker for the physiologic initiation of the swallow. Contraction of the tongue base and suprahyoid muscles pulls the hyoid bone up and forward, which in turn causes the epiglottis to close and the UES to open. Thus, the anterior and superior displacement of the hyoid is essential for protection of the airway during the swallow and for safe and efficient passage of the bolus into the esophagus [3, 4].

Several authors have reported on vertical and anterior displacement of the hyoid bone in normal subjects. Ishida et al. [5] reported means and standard deviations for vertical and anterior hyoid displacement during liquid and solid swallows in young, normal subjects. They reported a significant difference in hyoid excursion between liquid and solid consistencies. Solid food created more vertical and anterior displacement of the hyoid bone. Dodds et al. [6] and Cook et al. [7] added to that knowledge by reporting 
increases in hyoid excursion with increasing bolus volume. Bolus volumes may have different effects on vertical as opposed to anterior displacement. Logemann [8, 9] reported that younger male subjects have more vertical displacement of the hyoid than younger female subjects. However, older female subjects tend to have more anterior hyoid displacement than younger female subjects, presumably to compensate for age-related swallowing changes. Perlman et al. [10] reported that dyphagic patients had less displacement both anteriorly and vertically than normal subjects. No difference was observed between liquid and paste swallows.

The purpose of this study was to evaluate maximum excursion of the vertical and anterior displacement of the hyoid bone during normal swallowing. Means, standard deviations, and ranges were analyzed. Data from this study will be used for future comparisons of hyoid displacement in patients poststroke.

\section{Methods}

\section{Subjects}

Videotapes of video-fluoroscopic swallowing examinations (VFSE) were analyzed for 40 normal subjects. Subjects were divided into two age groups based on previous studies revealing age and gender differences $[2,8,9]$. Twenty were between the ages of 21 and 51, and 20 were between the ages of 70 and 87 . Ten women and ten men were analyzed in each age division (Table 1). Each subject passed a comprehensive questionnaire, a cranial nerve examination, and an oral motor/structural examination prior to participation in the study. Subjects with any neurologic or structural abnormality affecting the head and neck were excluded. Swallows analyzed for this report included two 5-ml and two 10-ml thin liquid boluses per subject, for a total of 160 swallows.

\section{Video-Fluoroscopic Swallowing Exam (VFSE)}

VFSE data were originally collected at the University of Tennessee Swallowing Research Laboratory [11]. Subjects were seated upright in a stretcher chair and filmed with a mobile, C-arm X-ray (OEC Diasonics, model 7600)

Table 1 The mean age (years) and the standard deviation (SD) of young and old subject groups

\begin{tabular}{lll}
\hline Groups & Mean (years) & SD (years) \\
\hline Young & 29.85 & 9.52 \\
Old & 77.20 & 6.85 \\
\hline
\end{tabular}

system. The study was recorded onto a Panasonic SuperVHS PV-S7670 Pro Line Multiplex video-cassette recorder. The fluoroscopic tube was focused in a lateral plane on the oral cavity from the lips anteriorly to the pharyngeal wall posteriorly, and from the nasopharynx superiorly to just below the UES area. Each subject swallowed two 5-ml and then two 10-ml thin liquid boluses (50/50 mixture of EZ-HD Barium Sulfate Powder for Suspension). Bolus viscosity was carefully controlled throughout the exam. Temperature of barium was held constant and viscosity was periodically rechecked with a Brookfield viscometer.

None of the subjects exhibited signs of dysphagia or aspiration during the VFSE. All swallows appeared to be normal for tongue base retraction, epiglottic inversion and seal, and UES opening.

Procedures for Biomechanical Measurement of Hyoid Excursion

This study focused on two types of biomechanical displacements of the hyoid excursion in normal swallowing: vertical and anterior. To accurately analyze the sequence of hyoid displacements, the VFSE S-VHS tapes were digitized using Adobe Premier Pro 1.5, a video-editing program, and a Sony DVMC-DA1 Media Converter. Two picture frames of VFSE were then generated for each swallow: one showing the resting position of the hyoid, and the other showing the maximum displacement of the hyoid bone during the swallow. Each picture frame was then submitted to the ImageJ $1.32 \mathrm{j}$ program [12]. Resting position and maximum displacement of the hyoid bone were determined after observing the whole swallow several times in real time and frame by frame. The resting position was marked as the moment just before the bolus is propelled in the oral cavity toward the pharynx. The investigators had three months of extensive training on biomechanical analysis of swallowing before joining this investigation.

Using ImageJ, each subject's picture frame was rotated to a true vertical $/ 90^{\circ}$ angle (Fig. 1). The angle of the line between the anterior-inferior corner of the cervical vertebrae 4 (C4) and inferior-anterior corner of C2 was used to rotate the image to the $90^{\circ}$ angle. This simplified the anterior and vertical displacement of the hyoid bone and assured the calculation relative to the vertebral column. In addition, the distance between the anterior-inferior corner and the anterior-superior corner of $\mathrm{C} 3$ was used as a distance marker $(15 \mathrm{~mm})$ for reference to hyoid displacement. This value was used because it was the average length of the vertebrae C3 from skeletons at the Swallowing Physiology Laboratory at Northwestern University [13]. The measurement was relative, rather than absolute. 
Fig. 1 a Rest frame of hyoid bone (R). b Maximum displacement frame of hyoid bone during the swallowing (M). anchor point: $\mathrm{C} 4$

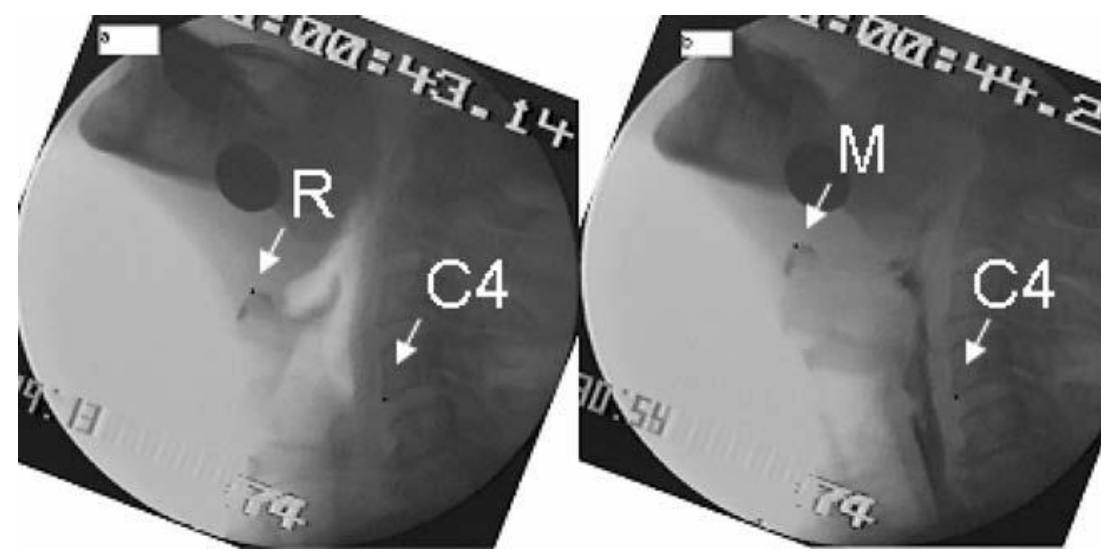

The following points were marked at each digitized picture frame: (1) a point on the anterior-inferior corner of $\mathrm{C} 4$, which served as an anchor point, (2-a) a point on the resting position of the hyoid bone or (2-b) a point on the most superior-anterior position of hyoid bone, which represented maximum displacement (Fig. 1). The ImageJ program provides the calculated values of each point $(x, y)$. The following formulas were used to measure how far the hyoid bone moved vertically and anteriorly. This analysis program was developed by Dr. Pauloski at Northwestern University.

anterior displacement :

$$
(x 2-x 1)-(C 4 x 2-C 4 x 1),
$$

vertical displacement :

$$
(y 2-y 1)-(C 4 y 2-C 4 y 1),
$$

where $\mathrm{x} 1$ and $\mathrm{y} 1$ are the starting (rest frame) coordinates of the structure of interest and $\mathrm{x} 2$ and $\mathrm{y} 2$ are the comparison image coordinates (e.g., maximum excursion coordinates). $\mathrm{C} 4 \mathrm{x} 1$ and $\mathrm{C} 4 \mathrm{y} 1$ are the coordinates of the anchor point in the rest frame, and $\mathrm{C} 4 \mathrm{x} 2$ and $\mathrm{C} 4 \mathrm{y} 2$ are the coordinates of the anchor point in the comparison frame.

For both anterior and vertical displacements of the hyoid bone during orophagrngeal swallowing, age and gender differences were analyzed using a one-way analysis of variance (ANOVA) for a repeated-measures, volume of bolus, and a two-factor ANOVA for age and gender. Wilkin's Lambda was used to determine the significance $(p<0.05)$.

Results

Reliability

For intrajudge reliability, the investigator randomly selected and reanalyzed $20 \%$ of the patients' VFSE tapes. This included 8 subjects and 32 swallows. A significant correlation between the first and second judgment was observed $(r=0.88, p W 0.01)$. For interjudge reliability, a second judge analyzed $20 \%$ of the subjects' video tapes. The second judge, who had undergone training on VFSE biomechanical measures for another investigation, reanalyzed the eight subjects. That judge's results were compared with the results of the primary investigator. A significant correlation was observed between judges $(r=0.83, p W 0.01)$.

Age

Means, standard deviations, and ranges for anterior and vertical disnlacement. of the hvoid hone. senarated into the

age categories for the younger and older subjects, are presented in Table 2 . Anterior displacement of the hyoid $(F(1,36)=7.17, p=0.01)$ was significantly different between younger and older subjects. Younger subjects had a mean anterior displacement of $1.63 \mathrm{~cm}$ for $5-\mathrm{ml}$ boluses and $1.80 \mathrm{~cm}$ for $10-\mathrm{ml}$ boluses. Subjects in the older age group had a mean anterior displacement of $1.16 \mathrm{~cm}$ for 5 $\mathrm{ml}$ boluses and $0.98 \mathrm{~cm}$ for $10-\mathrm{ml}$ boluses. For both 5- and 10 -ml volumes of thin liquid, the younger subjects exhibited greater anterior displacement than subjects in the older age group. Vertical displacement of the hyoid

Table 2 Mean, standard deviation (SD), and range $(\mathrm{cm})$ of the hyoid displacement for young and old age groups

\begin{tabular}{llcccc}
\hline Groups & Measurements & $5 \mathrm{ml}$ & $10 \mathrm{ml}$ & $5 \mathrm{ml}$ & $10 \mathrm{ml}$ \\
\hline \multirow{2}{*}{ Young } & Mean & 1.62 & 1.80 & 1.58 & 1.64 \\
& SD & 0.44 & 0.42 & 0.69 & 0.84 \\
& Range & 1.48 & 1.49 & 2.47 & 3.21 \\
\multirow{4}{*}{ Old } & Mean & 1.17 & 0.99 & 1.45 & 1.53 \\
& SD & 0.55 & 0.44 & 0.66 & 0.63 \\
& Range & 1.85 & 1.76 & 2.35 & 2.24 \\
\hline
\end{tabular}


$(F(1,36)=0.04, p=0.83)$ was slightly greater for young versus older subjects, but the difference was not significant. These data are provided as a bar graph in Figure 2.

Gender

Means and standard deviations (SD) for anterior and vertical displacement of the hyoid bone by gender are presented in Table 3. Males had mean anterior displacements of $1.20 \mathrm{~cm}$ for $5-\mathrm{ml}$ boluses and $1.30 \mathrm{~cm}$ for $10-\mathrm{ml}$ boluses and mean vertical displacements of $1.50 \mathrm{~cm}$ for 5$\mathrm{ml}$ boluses and $1.53 \mathrm{~cm}$ for $10-\mathrm{ml}$ boluses. Females had mean anterior displacements of $1.59 \mathrm{~cm}$ for $5-\mathrm{ml}$ boluses and $1.48 \mathrm{~cm}$ for $10-\mathrm{ml}$ boluses and mean vertical displacements of $1.52 \mathrm{~cm}$ for $5-\mathrm{ml}$ boluses and $1.63 \mathrm{~cm}$ for $10-\mathrm{ml}$ boluses. None of the differences observed for either anterior or vertical displacement were significant for a gender effect. These data are provided as a bar graph in Figure 3.

\section{Discussion}

Vertical and anterior displacement of the hyoid bone contributes to airway protection and bolus transport to the esophagus. More specifically, displacement of the hyoid facilitates epiglottic tilt and seal over the laryngeal vestibule, enhancing protection of the larynx from the bolus, and eases bolus transport to the esophagus by pulling the

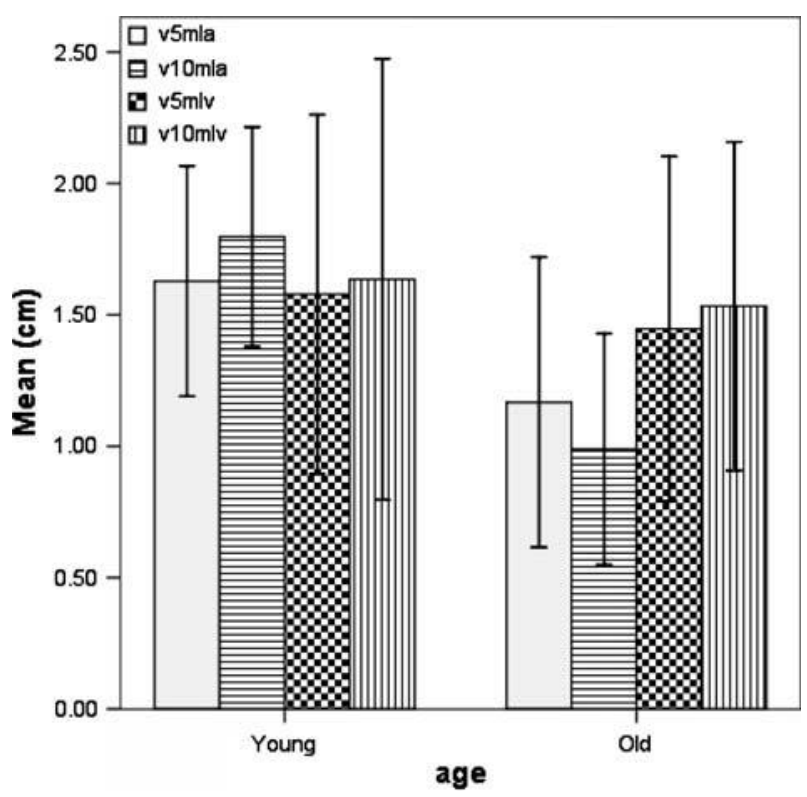

Fig. 2 Mean and standard deviation of the hyoid bone displacement (in $\mathrm{cm}$ ) by young and old age groups. $\mathrm{v} 5 \mathrm{mla}=$ volume $5 \mathrm{ml}$ anterior; $\mathrm{v} 5 \mathrm{mlv}=$ volume $5 \mathrm{ml}$ vertical displacement
Table 3 Mean, standard deviation (SD), and range $(\mathrm{cm})$ of the hyoid displacement by male and female subjects

\begin{tabular}{llcccc}
\hline Groups & Measurements & $5 \mathrm{ml}$ & $10 \mathrm{ml}$ & $5 \mathrm{ml}$ & $10 \mathrm{ml}$ \\
\hline Male & Mean & 1.20 & 1.30 & 1.50 & 1.53 \\
& SD & 0.56 & 0.68 & 0.63 & 0.69 \\
& Range & 1.99 & 2.33 & 2.35 & 2.12 \\
Female & Mean & 1.59 & 1.48 & 1.52 & 1.63 \\
& SD & 0.46 & 0.50 & 0.71 & 0.84 \\
& Range & 1.61 & 1.76 & 2.47 & 3.21 \\
\hline
\end{tabular}

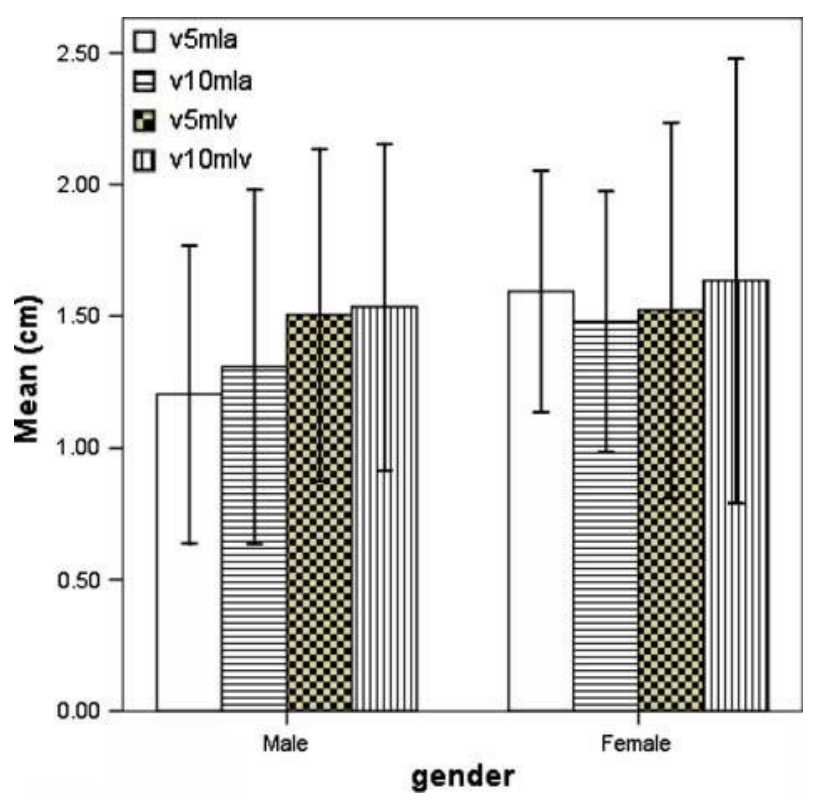

Fig. 3 Mean and standard deviation of the hyoid bone displacement (in $\mathrm{cm}$ ) for male and female groups. v5mla $=$ volume $5 \mathrm{ml}$ anterior; $\mathrm{v} 5 \mathrm{mlv}=$ volume $5 \mathrm{ml}$ vertical displacement

cricopharyngeus muscle open within the context of a relaxed UES [1, 3, 4]. It has been suggested that the vertical displacement of the hyoid is more associated with the closure and protection of the laryngeal vestibule and that the anterior displacement is more associated with the pulling motion on the cricopharyngeus that allows its opening within the UES [1].

Age

The results of this study showed that there was a significant difference between younger and older subjects for anterior displacement of the hyoid bone during the swallow but not for vertical displacement. Researchers previously demonstrated that as people get older, laryngeal elevation and initiation of maximum hyoid excursion may be delayed due 
to changes in motor and sensory functions [9, 11, 14]. Results of this study demonstrate that as people get older, anterior hyoid displacement is also reduced. Vertical hyoid displacement, on the other hand, appears to be maintained.

More specific causes of decline in swallowing function with age have been postulated. Robbins et al. [14] observed that maximal lingual pressures decline with age. Among reasons proposed were reduced muscle mass [16], changes in fiber density [16], and reduced numbers of functional motor units [17]. It has been suggested, as well, that some mechanism of the central nervous system may be less able to distinguish a distinct signal from noise in the system [18]. Thus, as people get older, the suprahyoid muscles, which pull the hyoid bone anteriorally and superiorly, may also become weaker. This should, at least superficially, create problems with both aspects of hyoid displacement. However, despite the fact that most suprahyoid muscles play a role in both types of displacement, more suprahyoid muscles are involved in vertical displacement than anterior displacement. Thus, it is possible that vertical displacement of the hyoid, with more muscles involved, is more protected against fatigue. Whereas, anterior displacement, with fewer muscles involved, may be more susceptible to fatigue that results from normal aging processes and the effects on functional motor units. If vertical displacement is truly more important for protection of the airway, then the greater number of muscles recruited for the activity may be a natural protective mechanism, as is likely the case with bilateral cortical innervations of the cranial nerves and other forms of natural protection or functional reserve. This becomes especially important when considered in conjunction with delayed initiation of the hyolaryngeal excursion (prolonged pharyngeal delay time) also associated with age [14], which further places patients at risk for aspiration.

Decreased anterior displacement of the hyoid with age does create a certain amount of risk, in and of itself, related to swallowing. Cricopharyngeal opening within the relaxed UES is critical to safe and efficient bolus transport, and increases in pharyngeal residue with age may result in penetration or aspiration [19]. It may be that less UES opening is required for individuals as they age. Cricopharyngeal muscle fibers may also weaken, requiring less pull from the suprahyoids to decrease resistance. This makes sense when considering the increased risk for gastroesophageal reflux at the hypopharnyx with increasing age [20, 21]. Slower bolus transit [2] and an increase in the number of swallows per bolus, which has been reported with age [20], may be natural compensations for decreased anterior displacement of the hyoid and the potential buildup of pharyngeal residue. It is necessary to measure the UES opening with these subjects. This will provide a more detailed explanation of the relationship between anterior displacement and UES opening. More research on these mechanisms between UES pressure changes with aging is needed.

Regardless of the potential outcomes, the effects of aging are evident in hyoid excursion during the swallow. With prolonged pharyngeal delay times and increases in pharyngeal residue, there may be an increased risk for aspiration, especially when secondary disease sets in.

\section{Gender}

Biomechanical measurements of vertical and anterior hyoid displacement demonstrated no significant differences between men and women. Mixed results have previously been reported by Logemann et al. [9]. In that investigation, gender differences were observed in younger subjects for vertical hyoid displacement with 1-ml boluses but not 10$\mathrm{ml}$ boluses. For older subjects there were significant gender differences in superior displacement with 10-ml swallows but not 1-ml swallows. The current study reported slightly longer vertical displacements for women in general, but the results were not significant. Considering the mixed results in Logemann et al. [9], the current results are not ostensibly contradictory.

\section{Summary}

Research regarding the biomechanical measurements of swallowing is essential for providing clinicians with direction in developing management and treatment plans specific to the type of swallowing problem. The vertical and anterior displacement of the hyoid bone has two main effects during the pharyngeal swallow. The vertical displacement of the hyolaryngeal structure contributes primarily to epiglottic and laryngeal closure to protect the airway from penetration or aspiration, and anterior displacement contributes primarily to opening of the UES, allowing passage of the bolus into the esophagus. The results of this study demonstrate that older subjects have reduced anterior displacement of the hyoid bone with relative preservation of vertical displacement. This may be related to the number of muscle fibers recruited for each task. These findings help explain previous reports that airway protection is maintained (vertical displacement of hyoid) in the face of reduced duration and extent of UES opening and increases in pharyngeal residue (anterior displacement of the hyoid). Because other factors play a role in bolus passage through the UES, such as UES relaxation and bolus volume/pressure, more research is needed to clarify the role of anterior hyoid excursion and the aging swallow on UES dysfunction. 
This study has several limitations, including a relatively small number of subjects and VFSE data derived from a previous investigation. In addition, the future VFSE study should include the calibrator to measure the exact displacement of the hyoid bone. Future research should evaluate these measures for their ability to distinguish between aspirators and nonaspirators in patients with dysphagia.

\section{References}

1. Logemann JA, Evaluation and Treatment of Swallowing Disorders. Austin, TX: Pro-ed, 1998.

2. Robbins JA, Hamilton JW, Lof GL, Kempster GB. Oropharyngeal swallowing in normal adults of different ages. Gastroenterology 1992;103:823-829.

3. Cook IJ, Dodds WJ, Dantas RO, Kern MK, Massey BT, Shaker R, Hogan WJ. Timing of videofluoroscopic, manometric events, and bolus transit timing during the oral and pharyngeal phases of swallowing. Dysphagia 1998;4:8-15.

4. Jacob P, Kahrilas PJ, Logemann JA, Shah V, Ha T. Upper esophageal sphincter opening and modulation during swallowing. Gastroenterology 1989;97(6):1469-1478.

5. Ishida R, Palmer JB, Hiemae KM. Hyoid motion during swallowing: factors affecting forward and upward displacement. Dysphagia 2002;17:262-272.

6. Dodds WJ, Man KM, Cook IJ, Kahrilas PJ, Stewart ET, Kern MK. Influence of bolus volume on swallow-induced hyoid movement in normal subjects. AJR Am J Roentgenol 1998;150(6):1307-1309, 2002.

7. Cook IJ, Dodds WJ, Dantas RO, Massey BT, Kern MK, Lang IM, Brasseur JG, Hogan WJ. Opening mechanisms of the human upper esophageal sphincter. Am J Physiol 1989;257(20):G748G759.

8. Logemann JA, Pauloski BR, Rademaker AW, Colangelo LA, Kahrilas PJ, Smith CH. Temporal and biomechanical characteristics of oropharyngel swallow in younger and older men. J Speech Lang Hear Res 2000;43(5):1264-1274.

9. Logemann JA, Pauloski BR, Rademaker AW, Kahrilas PJ. Oropharyngeal swallow in younger and older women: videofluoroscopic analysis. J Speech Lang Hear Res 2002;45(3): 434-445.

10. Perlman AL, VanDaele DJ, Otterbacher MS. Quantitative assessment of hyoid bone displacement from video images during swallowing. J Speech Lang Hear Res 1995;38(3):579-585.

11. McCullough GH, Wertz RT, Rosenbek JC. Age, gender, size, consistency effects on swallowing function in adults between 21 and 99 years of age. Presented to the 10th Annual Meeting of Dysphagia Research Society, Albuquerque, NM, 2001.

12. Rasband W, ImageJ v1.36b, March 13, 2006. Available at http://www.rsb.info.nih.gov/ij/ [accessed September 1, 2006].

13. Pauloski BR, Logemann JA, Fox JC, Colangelo LA. Biomechanical analysis of the pharyngeal swallow in postsurgical patients with anterior tongue and floor of mouth resection and distal flap reconstruction. J Speech Lang Hear Res 1995;38:110123.

14. Kim Y, McCullough GH, Asp CW. Temporal measurements of pharyngeal swallowing in normal populations. Dysphagia 2005;20:290-296.

15. Robbins JA, Levine R, Wood J, Roecker EB, Luschei E. Age effects on lingual pressure generation as a risk factor for dysphagia. J Gerontol 1995;50(5):M257-M262.

16. Campbell MJ, McComas AJ, Petito F. Physiological changes in aging muscles. J Neurol Neurosurg Psychiatry 1973;36:151-154.

17. Price PA, Darvell BW. Force and mobility in the aging human tongue. Med J Aust 1981;1:75-78.

18. Welford AT. Between bodily changes and performance: some possible reasons for slowing with age. Exp Aging Res 1984;10:73-88.

19. McCullough GH, Rosenbek JC, Wertz RT, Suiter D, McCoy S. Defining swallowing function by age: Promises and pitfalls of pigeonholing. Top Ger Rehabil 2007;23(4):290-307.

20. Cho YS, Choi MG, Jeong JJ, Chung WC. Prevalence and clinical spectrum of gastroesophageal reflux: a population-based study in Asan-si, Korea. Am J Gastroenterol 2005;100(4):747-753.

21. Locke GR, Talley NJ, Fett SL, Zinsmeister AR, Melton LJ. Prevalence and clinical spectrum of gastroesophageal reflux: a population-based study in Olmsted County, Minnesota. Gastroenterology 1997;112(5):1448-1456. 